Innovative Australier

\title{
Hautkrebs per SMS verhindern
}

In kaum einem anderen Land der Welt gibt es so viele Melanomfälle wie in Australien. Kein Wunder, dass die australischen Behörden nichts unversucht lassen, die Prävention zu verbessern. Eine mögliche Hilfe könnten regelmäßige SMS-Erinnerungen sein.

In einer australischen Studie (Youl PH et al.: Can skin cancer prevention and early detection be improved via mobile phone text messaging? A randomised, attention control trial. Prev Med 2015; 71:50-6) erhielten 546 Freiwillige zwischen 18 und 42 Jahren über einen Zeitraum von zwölf Wochen wöchentlich eine SMS, danach einmal im Monat. Die Teilnehmer wurden zufällig auf drei Gruppen verteilt: Gruppe 1 erhielt regelmäßig Kurznachrichten, in denen dazu aufgefordert wurde, Sonnenschutz zu verwenden.

Freiwillige aus Gruppe 2 sollten ihre Haut regelmäßig nach auffälligen Veränderungen absuchen - oder jemand anderen, etwa ihren Partner, darum bitten. Die Kontrollgruppe 3 erhielt den Auftrag, sich körperlich zu betätigen. Nach einem Jahr wurden alle Teilnehmer telefonisch befragt.

In Gruppe 1 und 2 verbesserten sich — nach Aussage der Freiwilligen die Sonnenschutzmaßnahmen deutlich im Vergleich zur Kontrollgruppe. Nach dem Jahr untersuchten beispielsweise $63 \%$ der Teilnehmer aus Gruppe 2 regelmäßig ihre Haut, im Vergleich zu 27 \% vor Studienbeginn. Die Autoren der Studie wollen die Methode ausbauen und in Zukunft individualisierte Kurznachrichten sowie MultimediaInhalte (z.B. per MMS) verschicken.

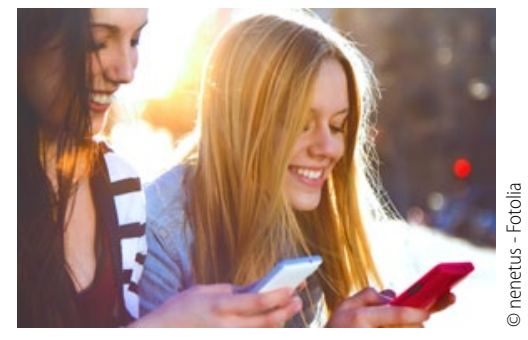

Der Originalbeitrag von Sebastian Lux erschien in "hautnah dermatologie" 2/2015, DOI: 10.1007/s15012-015-1775-2, (c) Springer Verlag

hautnah $2015 \cdot 14: 21$ DOI 10.1007/s12326-015-0161-5 Online publiziert: 22. April 2015 ○) Springer-Verlag Wien 2015

\section{Hier steht eine Anzeige.}

